missures between them ; excepting in the case of aphemia, where, as stated, it is in the internuncial fibres passing from the third frontal convolution to the motor centres in the bulb. The fact that a paralytic disability is produced does not in any way prove that it is not due to a defect in a sensory centre, or in a commissure between two such centres; it is here, in fact, that we have to look for the sources of the volition.

\title{
Studies on Ulcus Ventriculi Simplex, Gastromalacia, and Ileus.
}

TALMA (Zeitschr.f. klin. Med., 1890, xvii. 10) reviews briefly some of the various views which have been held regarding the mode of origin of ulcer of the stomach and of gastromalacia, showing that even yet little definite knowledge is possessed regarding it, and that the majority of writers consider that gastromalacia never occurs before death.

The author has undertaken a series of experiments upon animals with reference to this subject and to the relation of these lesions to ileus. These he reports in detail. The procedure followed consisted in the ligation of various parts of the intestinal tract; sometimes of the esophagus and duodenum, sometimes of the duodenum alone or of some other part of the large or small intestine, sometimes in the separation of a loop of small intestine by a double ligation. Great swelling of the abdomen resulted in nearly every instance; due almost always to accumulation of fluid above the ligature. Gas was found in some cases, partly the result of the swallowing of air, partly due to fermentation. Investigations showed that these fluid contents of the intestinal tract consisted chiefly of the gastric secretion. The amount of hydrochloric acid poured out after the ligation of the duodenum appeared to be abnormally great. If the ligature was lower in the intestine, the secretion of the intestinal glands was also present, but it is uncertain what proportion of the fluid this formed. The nature of the fluid poured out by the intestine, and the character of the lesions seen both above and below the point of ligation seemed to depend largely upon the character of the gastric and intestinal contents at the time the experiment was made. Whatever the correct explanation may be, it is certain that very grave alterations often develop in the portion of the intestine below the ligature.

The results of closure of the large intestine were somewhat different from those just described. The animals lived longer, the distention of the abdomen was not so marked, and the fluid had accumulated in the large intestine, leaving the small intestine and stomach entirely empty. The marked power of the large intestine to absorb water was doubtless the reason that no more fluid was present. Fæcal changes take place in the substances blocked up in either the large or small intestine, but not in a loop of the bowel which has been cut off by a double ligature. From this the author concludes that the change is either due to ferments introduced with the food, or that it can take place only in ingesta which have undergone a certain degree of alteration. The production of the fæcal character took place first in the portion of the contents nearest to the ligature.

The curative influence of vomiting was seen in the fact that rabbits, which do not vomit, died quickly through overfilling of the stomach, while dogs lived several days, because they do vomit. The practical deduction from this is that patients with ileus, who vomit with not too great labor, should frequently 
have administered to them large amounts of warm water, combined with the employment of other uninjurious means of inducing vomiting. In nearly all the rabbits experimented on there was a profuse secretion of mucus. The object of this was clearly to protect the delicate glandular tissue from injurious influences. The cause of death in his experiments appeared to be nearly always the absorption of material from the intestine poisoning the economy.

The studies of the author lead him to the following conclusions more directly bearing upon the nature and cause of gastromalacia and ulcer of the stomach. He claims that gastromalacia develops under two circumstances: 1 , the presence of chemically-altered gastric contents; 2 , a high tension of the stomach wall. As a result of the latter there are produced in the gastric wall, especially in the mucosa, widespread hæmorrhagic infiltrations, necrosis, etc. Gastric contents, containing even a very small amount of hydrochloric acid, produce changes in the soft parts. The stronger the chemical action of the secretion the more rapidly do infiltration and necrosis and also the softening follow. Gastromalacia, as seen in rabbits experimented on, occurs principally in the fundus, since the resistance of the muscular wall to the pressure is least here, and the circulation is most interfered with; the interference with the circulation is the chief cause of hæmorrhages, etc. The great stretching of the wall of the fundus, and probably of the bloodvessels contained in it, is the reason that the gastromalacia is found only in this region. Probably the less degree of resistance of the mucosa in this part is not without influence. The malacia is denominated "white" when it develops without previous hæmorrhage.

In addition to the malacia, ulcers in various stages of development are found. These are due to extreme restriction of the circulation. Through this restriction there can either arise: 1. Large hæmorrhages under the mucosa, separating it from the muscular layer and causing its death; or, 2. Hæmorrhages into the mucosa, likewise producing its necrosis. As a result of softening of the necrotic parts under the influence of the gastric secretion, larger or smaller ulcers are produced.

Often, however, ulcers arise without previous hæmorrhage; and these are to be regarded as the result of softening.

The deductions from these experiments and from the nature of the isolated cases which have been reported lead the author to the conclusion that the brown gastromalacia arises in man usually, if not always, during life; though death may so rapidly follow that there is no time for the development of secondary inflammations and the like. Autopsies show that malacia in man is situated nearly invariably in the fundus.

With regard more particularly to the production of ulcus ventriculi in men, the author reports several cases in which painful tonic spasmodic con. traction of the stomach wall-not the intermittent peristaltic contractionwas almost certainly the cause of ulceration and hæmorrhage; and he further refers to the frequency with which spasm of the stomach is witnessed in hysterical women, diseases of the central nervous system, and hypersecretion of the gastric juice.

Experiments were then made on animals to determine the cause and nature of this gastric spasm; and these appeared to prove that irritation of the left vagus developed a powerful contraction of the stomach, which, if long-continued, would produce round ulcer of the stomach, penetrating 
the mucosa, and sometimes the muscular layer. It seemed, in fine, proven that the contraction of the wall of the stomach in the pyloric region was soon followed by necrosis of the mucosa, and this by the development of an ulcer. The pressure upon the bloodvessels, and especially upon the arteries, must come into play here, for, if the movement of the blood in the veins were disturbed more than that in the arteries, hæmorrhages would be found in various portions. The occurrence of hæmorrhages shows, however, that the veins do not entirely escape the pressure of the muscular layer. The great likeness between the symptoms after which, and the place where, ulcer of the stomach appears in both the rabbits experimented on and in man, justifies the conclusion that the genesis of both is the same; and that ulceration and hæmorrhage occurring in men after gastric spasm are the result of arterial anæmia produced by the pressure of the contracting muscular layer of the stomach. When hypersecretion of hydrochloric acid and gastric spasm occur together the conditions are those most fitting for the production of ulcer. The author believes that an excess of hydrochloric acid is often the cause of gastric spasm; but that it is not always the cause is shown by the fact that the administration of large amounts of fluid with carbonate of soda does not always prevent the attacks, and sometimes even seems to increase them. Nor does he claim that every case of ulcer is due to gastric spasm, though very many instances can be explained in no other way. That the ulcers occur almost always in the pyloric region is due to the fact that the muscular contraction is strongest here. When the contraction of the walls of the fundus is unusually strong, ulcers may occur there also.

The condition of the ulcers after once formed is still an undecided question. It has generally been claimed that they showed no tendency to heal, and that they may last for even twenty years or more. The author is, however, inclined to the view that the instances of vomiting of blood after long intervals of freedom from it are simply instances of the formation of new ulcers under the influences of the old causes, the old ulcers having healed. He thinks it improbable, if not impossible, that the functions of the stomach could continue normal between the attacks, if the ulcer were still existing.

\section{S UR G E R Y}

\section{UNDER THE CHARGE OF}

J. WILLIAM WHITE, M.D., PROFEGSOR OF CLINICAL SURGERY IN THE UNIVERSTTY OF PENNBYLVANIA: BURGEON TO THE UNIYRESITY AND GERMAN HOBPITALE.

Assisted BY.

EDWard Martin, M.D., BURGEON TO THE HOWARD HOSPTTAL AND ABSIBTANT SURGEON TO THE UNIVERSITY HOSPITAL.
Charles B. Penrose, M.D., BURGEON TO THE GYNECEAN AND GRRMAN Hospitals.

\section{Gluck's Method of Inserting Ivory JoInts as a Substitute for} EXCISED ONES.

DR. GLuCK's claim (British Medical Journal, No. 1550) to be able to implant pieces of bone and even whole joints, has naturally excited not ouly 